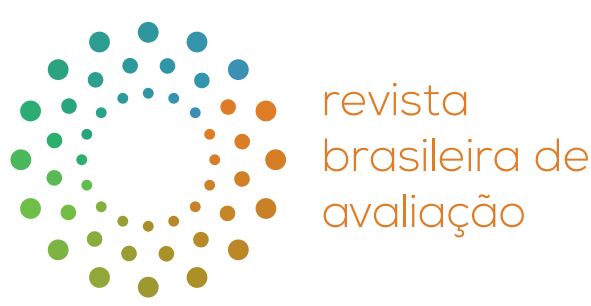

\title{
Relato de percurso metodológico multidimensional na escola Alan Pinho Tabosa
}

\author{
Report of the multidimensional methodological course at the Alan \\ Pinho Tabosa school
}

\author{
Talita Feitosa de Moisés Queiroz ${ }^{1 *}$ (1) [Negra Parda], Verônica Salgueiro do Nascimento ${ }^{1}$ (1) [Branca] \\ ${ }^{1}$ Universidade Federal do Ceará (UFC), Programa de Pós-graduação em Avaliação de Políticas Públicas, Fortaleza, CE, \\ Brasil
}

COMO CITAR: Queiroz, Talita Feitosa de Moisés, \& Nascimento, Verônica Salgueiro do. (2021). Relato de percurso metodológico multidimensional na escola Alan Pinho Tabosa. Revista Brasileira de Avaliação, 10(2), e101421. https://doi.org/10.4322/rbaval202110014

\section{Resumo}

Este estudo apresenta o relato de um exercício investigativo a partir de pressupostos da avaliação em profundidade, na realização de pesquisa de mestrado em curso na Escola Estadual de Educação Profissional Alan Pinho Tabosa (Pentecoste-CE). A escola surgiu de uma peculiar parceria entre a Universidade Federal do Ceará, a Secretaria Estadual de Educação e o Movimento Prece. Tendo em vista a complexidade de tal tessitura, optou-se pela avaliação em profundidade por esta apresentar dimensão epistemológica multidimensional e experiencial, explícito compromisso ético-político e etapas metodológicas multianalíticas que delineiam contexto, conteúdo, trajetória institucional e espectro temporal-territorial dos sujeitos que utilizam a política. Dessa forma, indica uma perspectiva avaliativa multidimensional para o fortalecimento das políticas públicas, tão necessária aos desafios presentes.

Palavras-chave: Avaliação de Políticas Públicas. Avaliação multidimensional. Avaliação em Profundidade. Política de Educação. Escola Pública.

\begin{abstract}
The study seeks to present a report of an investigative exercise from on the assumptions of the Avaliação em Profundidade [In-depth evaluation] in conducting master's research to take place at the Escola Estadual de Educação Profissional Alan Pinho Tabosa (Municipality of Pentecoste, State of Ceará, Country Brazil). The school arises from a peculiar partnership between the Universidade Federal do Ceará, the Secretaria Estadual de Educação and the Movimento Prece. In view of the complexity of such a fabric, avaliação em profundidade was chosen because it presents a multidimensional and experiential epistemological dimension, explicit ethical-political commitment and multi-analytical methodological steps, which outline the context, content, institutional trajectory and temporal-territorial spectrum of the subjects that use politics. Thus, it indicates a evaluative perspective for strengthening public policies, so necessary to the current challenges.
\end{abstract}

Keywords: Public Policy Evaluation. Multidimensional evaluation. Avaliação em Profundidade [In-Depth evaluation]. Education Policy. Public school.
A RBAVAL apoia os esforços relativos à visibilidade dos autores negros na produção científica. Assim, nossas publicações solicitam a autodeclaração de cor/etnia dos autores dos textos para tornar visível tal informação nos artigos.

Recebido: Julho 27, 2021

Aceito: Agosto 02, 2021

*Autor correspondente:

Talita Feitosa de Moisés Queiroz

E-mail: talitafdemoises@gmail.com

\section{(cc) BY}

Este é um artigo publicado em acesso aberto (Open Access) sob a licença Creative Commons Attribution, que permite uso, distribuição e reprodução em qualquer meio, sem restrições desde que o trabalho original seja corretamente citado. 


\section{Introdução}

O Século XXI tem trazido transformações tecnocientíficas e psicossociais inimagináveis, gerando um verdadeiro abismo intergeracional (Castro, 2006). A escola pública é um dos principais palcos desses conflitos entre as diferentes gerações, tendo o permanente desafio de atualizar suas proposições, estabelecendo diálogos para a tessitura das políticas públicas voltadas às juventudes.

É entendendo a relevância do papel social da escola pública que esta pesquisa em avaliação de políticas públicas, ainda em andamento, vem se desenvolvendo com o objetivo de avaliar as contribuições da Escola Estadual de Educação Profissional Alan Pinho Tabosa para política de educação.

A escolha por este equipamento dá-se pelo curioso arranjo de sua implementação através de uma parceria entre a Secretaria de Educação do Estado do Ceará (SEDUC), a Universidade Federal do Ceará (UFC) e o Movimento Prece do Instituto Coração de Estudante (Movimento Prece/lcores), um ente da sociedade civil organizada que se originou de associações estudantis de comunidades rurais do município de Pentecoste-CE (Ribeiro, 2018).

Também demarca essa opção a vinculação da pesquisadora com a referida experiência, tendo sido participante como estudante secundarista do Movimento Prece, como universitária extensionista da UFC e profissional da SEDUC, de maneira que presenciou e contribuiu com a implantação da EEEP Alan Pinho Tabosa.

Tendo isso em vista, percebeu-se que a experiência interinstitucional da referida escola seria melhor compreendida a partir de uma abordagem qualitativa, participativa e multidimensional, o que levou à adoção, nesta pesquisa avaliativa, de pressupostos da avaliação em profundidade sistematizada por Rodrigues (2016) que traz percepções históricas e multidimensionais para o processo avaliativo das políticas públicas. Este trabalho objetiva compartilhar as etapas metodológicas que têm sido utilizadas na realização dessa pesquisa para contribuir com a discussão de modelos e desenhos avaliativos multidimensionais nas políticas públicas.

\section{Paradigmas avaliativos multidimensionais: perspectiva da avaliação em profundidade}

A avaliação de políticas públicas é uma demanda atual e traz à discussão uma enorme pluralidade de concepções que permeiam esse campo. Essa diversidade de pensamento é fundamental para construção de novos caminhos epistemológicos e novas implicações políticas e sociais da pesquisa.

Conforme alerta Morin (2003), partindo de sua concepção do Pensamento Complexo, é preciso cautela para não cair no erro de simplificar o mundo em função da simplicidade da ciência adotada. Bourdieu (1989, p. 26) corrobora esta mesma ideia ao escrever que “[...] a pesquisa é uma coisa demasiado séria e demasiado difícil para se poder tomar a liberdade de confundir a rigidez, que é o contrário da inteligência e da invenção, com o rigor". Ele afirma ser este o grande desafio para os principiantes no verdadeiro ofício de pesquisador: deixar de lado o saber já estabelecido e aceito e arriscar-se diante do saber que se apresenta na realidade.

Nessa perspectiva, Kuhn (2013) desenvolve a discussão que toda pesquisa é constituída a partir de um paradigma de ciência, um modo específico de se entender o que é a realidade, como pode ser apreendida, para que e para quem o conhecimento está a serviço. Prosseguindo nesse debate, Denzin e Lincoln (2012) citam alguns paradigmas ícones e suas características, como positivismo, pós-positivismo, teoria crítica, construtivismo e pós-construtivismo. É neste último, também nomeado por eles de paradigma participativo, que a avaliação em profundidade vai encontrar maior consonância, embora sejam possíveis outras confluências com pressupostos da teoria crítica e do construtivismo. A seguir será feita breve discussão sobre as dimensões ontológicas, epistemológicas, ético-políticas e metodológicas da avaliação em profundidade. 
A ciência moderna constituiu-se a partir dos pressupostos positivistas, que abriu caminhos alternativos às explicações místicas sobre o mundo. Nesse esforço assumiu em sua dimensão ontológica uma visão realista e dualista sobre a realidade, como se fosse possível extrair "verdades" por meio da investigação científica (Denzin \& Lincoln, 2012). E estabeleceu para si axiomas epistemológicos tais como postura neutra do pesquisador, elaboração de hipóteses prévias, realização de experimentos e testes, análises e provas estatísticas (Rodrigues, 2016).

Guardada a relevância histórica e sua indiscutível importância para o estabelecimento do método científico, a lógica linear do paradigma positivista não dá conta da complexidade de alguns fenômenos, especialmente quando se adentra no campo das relações humanas e sociais (Morin, 2003).

Dessa forma, partindo de outros pressupostos ontológicos e, por conseguinte, epistemológicos, tem-se o paradigma pós-construtivista, como no modelo experiencial apresentado por Lejano (2011) e que possui estreita similaridade com a avaliação em profundidade (Rodrigues, 2016). Em ambas, a dimensão ontológica aproxima-se de uma percepção sócio-histórica e participativa da realidade, segue uma epistemologia fundamentada em uma lógica não-linear, respeitando a multidimensionalidade dos fenômenos em que a interação do pesquisador durante a pesquisa é fundamental para o processo hermenêutico-holístico, tendo como critério de coesão a autenticidade descritiva da experiência (Rodrigues, 2016).

Nesse sentido "[...] uma análise de políticas deve considerar as múltiplas dimensões da experiência e do entendimento, atentando para a complexidade dos fenômenos - seu caráter processual, contextual, dinâmico e flexível" (Rodrigues, 2016, p. 105). Avaliar, partindo dessa abordagem, é um exercício etnográfico de apreensão dos significados e sentidos construídos de forma muito particular por aqueles que compõem a dinâmica de determinada política (Gonçalves, 2008; Gussi, 2014). Na avaliação em profundidade, o enfoque está na realidade empírica, experiencial, subordinando os aspectos formais ou idealizados da política àquilo que se apresenta na prática.

É interessante notar que modelos avaliativos focados na lógica de resultados, na produtividade e desempenho, na mensuração e fiscalização, na otimização de custo-benefício são massivamente implementados na avaliação das políticas públicas. Curiosamente, são modelos que atendem as demandas de grupos alinhados à nova gestão pública e perspectivas neoliberais de livre regulação do mercado (Gussi \& Oliveira, 2015). Vale salientar que o que aqui está sendo problematizado não são os modelos em si, mas a falta de clareza em explicitar os objetivos dos grupos que os financiam. Esse tipo de perspectiva, apesar de alegar uma pretensa neutralidade científica, subordina-se aos seus financiadores. E novamente a problemática reside em negar sua intencionalidade. Como denuncia Jannuzzi (2016, p. 126) "Reconhecer a natureza humana e idiossincrática da produção de conhecimento não o fragiliza. O que o enfraquece é a falta de transparência metodológica".

É partindo dessa compreensão que a avaliação em profundidade traz de forma explícita a dimensão ético-política para realização da avaliação, enfatizando a importância do papel do pesquisador em assumir que a produção científica não é feita de neutralidades, mas dos posicionamentos assumidos na pesquisa (Carvalho \& Gussi, 2011). É fundamental ao avaliador um olhar analítico para reconhecer os diferentes grupos de interesses e alocar-se de forma consistente a partir de um lugar de fala, admitindo que "Avaliação - e o avaliador - entra no jogo e, portanto, configura-se como um elemento integrante da arena política e da agenda governamental" (Gussi \& Oliveira, 2015, p. 4). O que fica posto de forma indubitável nessa abordagem é a indissociabilidade entre ciência e sua dimensão ético-política, como coloca Silva $(2012$, p. 224) "[...] uma concepção de pesquisa avaliativa enquanto ato técnico, mas também político".

Um aspecto elementar dessa dimensão é reconhecer os participantes em sua condição de sujeitos da pesquisa, realocando o pesquisador em uma função articuladora na co-construção do conhecimento e compromissos compartilhados. Como apresenta Cruz (2019, p. 14) "Assim, cabe ao pesquisador/avaliador perceber que a escolher a avaliação em profundidade ele rechaça a neutralidade científica e entende a política pública como instrumento de promoção de cidadania, justiça social, equidade e emancipação". 
Na dimensão metodológica, o desafio é integrar análise e avaliação, entendendo as relações de reciprocidade entre estes aspectos. Torna-se indispensável para avaliação um olhar analítico sobre as configurações do Estado contemporâneo e sua reverberação sobre as políticas públicas. De modo igualmente relevante está o uso de estratégias metodológicas que possibilitem adentrar as especificidades das trajetórias institucionais e os significados atribuídos pelos sujeitos que compõem determinada política, estabelecendo multirreferenciais para avaliação (Gussi \& Oliveira, 2015).

Nesse sentido Rodrigues (2016) apresenta quatro eixos analíticos a serem considerados no processo de avaliação de uma política pública.

- Eixo analítico do contexto de formulação da política. Diz respeito ao delineamento do momento histórico em que está inserida a política pública, sua conjuntura social, cultural e político-econômica, em um fluxo de compreensão que vai de macro contextos internacionais, transnacionais ou nacionais para microrrelações regionais, locais, institucionais ou específicas de um grupo de sujeitos. Assim, "[...] faz toda a diferença perceber como são acionados elementos de ordem simbólica - elementos étnicos e identitários; valores morais, cívicos e éticos; idéias e símbolos articulados a ideologias do progresso e da modernização, dentre outros" (Rodrigues, 2014, p. 181);

- Eixo analítico dos conteúdos da política. Trata-se de um levantamento dos principais marcos regulatórios de formulação, implantação, acompanhamento e avaliação da política a ser analisada em suas respectivas esferas governamentais. A proposta é que seja feita uma leitura analítica destes documentos, elencando seus principais autores, conceitos, idéias e valores presentes em tais escritos, podendo assim identificar quais os paradigmas orientadores da política e a verificação de sua coerência interna;

- Eixo analítico da trajetória institucional da política. Propõem-se a compreender as peculiaridades institucionais e seus deslocamentos ao longo do tempo, admitindo que, assim como cada pessoa tem uma trajetória biográfica singular, essas instituições também seguem múltiplos percursos e reconfiguram as políticas em função de suas variadas especificidades (Rodrigues, 2016; Gussi, 2014). Como destaca Gussi \& Oliveira (2015, p. 96) é importante que o avaliador entenda que a política "[...] não tem um sentido único e, portanto, está circunscrita a ressignificações de acordo com os fluxos organizacionais, processos burocráticos e modificações interpretativas";

- Eixo analítico do espectro temporal e territorial da política. Compreende as construções subjetivas dos sujeitos entrelaçados de forma temporal e territorial com a política. Como destaca Gonçalves (2008, p. 22-23) é uma dimensão analítica que vai além de indicadores estatísticos, mas volta-se à construção de indicadores socioculturais cujo objetivo é "[...] apreender a visão de mundo dos sujeitos sociais que são alvos das políticas públicas, além do modo como os ressignificam".

\section{Percursos metodológicos da investigação da experiência da EEEP Alan Pinho Tabosa}

Um primeiro movimento analítico implicou no levantamento dos principais marcadores temporais, políticos, econômicos e sociais que contextualizam a implantação da EEEP Alan Pinho Tabosa. O Quadro 1 é ilustrativo para visualização panorâmica de tais elementos.

O que se apreende do quadro é que no fim do século XX o advento das revoluções tecnológica/ digital, o crescente acúmulo de capital pela economia rentista e o estabelecimento de um modelo aberto da economia global estabeleceu de forma hegemônica o capitalismo financeiro no mundo e aos países periféricos, como o Brasil, imposta a adoção de uma política econômica neoliberal, de estado mínimo e privatizações (Mészáros, 2011).

Nesse contexto, os quatro mandatos consecutivos do Partido dos Trabalhadores (PT) de 2003 a 2016 centralizaram a economia brasileira nas demandas externas da exportação de commodities, enquanto a dinâmica interna foi alavancada pela ampliação de crédito e inserção no consumo das classes sociais antes excluídas (Paulani, 2012). Tal política econômica 
Quadro 1. Contextualização política, econômica e social.

\begin{tabular}{|c|c|c|c|c|c|c|}
\hline \multicolumn{2}{|c|}{ CRONOLOGIA } & \multirow{2}{*}{$\begin{array}{l}\text { 1990-1998 } \\
\text { Collor, Itamar, } \\
\text { FHC }\end{array}$} & \multirow{2}{*}{$\begin{array}{l}\text { 1999-2006 } \\
\text { FHC e Lula }\end{array}$} & \multirow{2}{*}{$\begin{array}{c}\text { 2007-2014 } \\
\text { Lula e Dilma }\end{array}$} & \multirow{2}{*}{$\begin{array}{r}\mathbf{2 0 1 4 - 2 0 1 6} \\
\text { Dilma e Temer }\end{array}$} & \multirow{2}{*}{$\begin{array}{l}\text { 2016-ATUAL } \\
\text { Temer e } \\
\text { Bolsonaro }\end{array}$} \\
\hline POLÍTICA & Presidência & & & & & \\
\hline & $\begin{array}{l}\text { Governo do } \\
\text { Estado do Ceará }\end{array}$ & Ciro/Tasso & Tasso/Lúcio & Cid & Cid/Camilo & Camilo \\
\hline \multirow[t]{2}{*}{ ECONÔMICA } & $\begin{array}{l}\text { Implantação } \\
\text { Financismo }\end{array}$ & Ajustes iniciais & $\begin{array}{l}\text { Consolidação de } \\
\text { ajustes financistas }\end{array}$ & $\begin{array}{l}\text { Brasil } \\
\text { Plataforma } \\
\text { Mundial }\end{array}$ & $\begin{array}{l}\text { Ortodoxia } \\
\text { Rentista }\end{array}$ & $\begin{array}{l}\text { Financismo } \\
\text { Radical }\end{array}$ \\
\hline & $\begin{array}{l}\text { Política } \\
\text { Econômica } \\
\text { Neoliberal }\end{array}$ & $\begin{array}{l}\text { Plano Real e } \\
\text { Estabilização da } \\
\text { economia }\end{array}$ & $\begin{array}{l}\text { Consumo das } \\
\text { Massas }\end{array}$ & $\begin{array}{l}\text { Ensaios } \\
\text { Neodesenvol- } \\
\text { vimentistas }\end{array}$ & $\begin{array}{l}\text { Congelamento de } \\
\text { gastos públicos }\end{array}$ & $\begin{array}{l}\text { Desmonte } \\
\text { de Direitos } \\
\text { - Estado } \\
\text { Necrófilo }\end{array}$ \\
\hline SOCIAL & $\begin{array}{l}\text { Formatações } \\
\text { dos movimentos } \\
\text { sociais }\end{array}$ & $\begin{array}{l}\text { Papel dos } \\
\text { movimentos } \\
\text { sociais na } \\
\text { constituinte }\end{array}$ & $\begin{array}{l}\text { Movimentos } \\
\text { sociais e o "Boom" } \\
\text { das ONGs }\end{array}$ & $\begin{array}{l}\text { Movimentos } \\
\text { Sociais em } \\
\text { Cargos dos } \\
\text { Governos }\end{array}$ & $\begin{array}{l}\text { Fragilização dos } \\
\text { Movimentos } \\
\text { Sociais }\end{array}$ & $\begin{array}{l}\text { Redes sociais e } \\
\text { manifestações } \\
\text { virtuais }\end{array}$ \\
\hline
\end{tabular}

FHC - Fernando Henrique Cardoso; ONGs - Organizações Não Governamentais.

Fonte: autoria própria.

possibilitou alguns avanços sociais, mas foi incipiente em proporcionar transformações estruturais. Outra marca característica desse momento é a inserção de lideranças dos movimentos sociais em cargos governamentais, o que também teve efeitos paradoxais ao enfraquecer as bases comunitárias (Dagnino, 2002). Dessa forma, o PT cumpriu a consolidação do neoliberalismo no Brasil (Calixtre \& Fagnani, 2017).

Uma segunda etapa foi de levantamento dos conteúdos sobre a política a partir de documentos oficiais, produções pedagógicas e produtos de mídia relacionados à escola. É importante demarcar que esta não se trata de uma leitura meramente informativa, mas de um procedimento que visa ir além do texto, clarificando o contexto em que está circunscrito, identificando seus autores, interlocutores e intencionalidades dentro de uma determinada conjuntura política e social (Gussi \& Oliveira, 2015).

Para compor um quadro das normativas oficiais, optou-se por elencar os marcos regulatórios da educação básica das Escolas Estaduais de Educação Profissional e do Ensino Superior nas respectivas esferas governamentais. Além disso, outros materiais também foram investigados, como cadernos, guias e orientações pedagógicas disseminados pela SEDUC, além do próprio Projeto Político Pedagógico desenvolvido pela EEEP Alan Pinho Tabosa e suas proposições de Aprendizagem Cooperativa e Solidária. Outra fonte secundária usada foram os materiais de produção escrita e áudios-visuais sobre a escola, em blogs, instagram, documentários, entrevistas, tipificando conteúdos que vem sendo publicizado pela EEEP APT nos diversos meios de comunicação em massa.

Uma terceira etapa consistiu na narrativa da trajetória institucional caracterizando as peculiaridades dessa escola. Para tanto se utilizou: (a) análise bibliográfica de pesquisas acadêmicas desenvolvidas sobre o Movimento Prece e a Aprendizagem Cooperativa, como Andrade Neto et al. (2019); Ribeiro (2018), Matos (2018), Barbosa (2016) e Bitu (2014); (b) análise documental com foco no resgate histórico principalmente a partir de depoimentos, entrevistas e produção autobiográfica (Andrade Neto, 2018) do idealizador e articulador dessa parceria, Professor Manoel Andrade'; (3) diário de campo viabilizado pela vinculação da pesquisadora com a EEEP APT, ocupando papel duplo de pesquisadora-participante. 


\section{Resultados parciais e discussões}

A partir das três etapas metodológicas mencionadas foi possível delinear compreensões sobre a experiência da EEEP Alan Pinho Tabosa a seguir descritas. Uma primeira compreensão diz respeito aos reflexos da política econômica do país e seus efeitos sobre as demais políticas públicas e sobre os arranjos sociais de cada período. O surgimento da EEEP Alan Pinho Tabosa está diretamente relacionado com o Movimento Prece, iniciativa que surgiu em 1994 em uma localidade rural chamada Cipó no Município de Pentecoste, localizado a 89 km de Fortaleza-CE.

Um grupo de sete jovens sem escolarização básica aceitou o convite do professor universitário Manoel Andrade, natural da comunidade, para estudarem juntos em uma casa de farinha abandonada para que dessa maneira pudessem concluir seus estudos e pleitear o ingresso na Universidade Federal do Ceará. O grupo se denominou Projeto Educacional Coração de Estudante, formando a sigla Prece e ao lograr êxito em seus objetivos acadêmicos passou a ter adesão de centenas de jovens da região (Andrade Neto et al., 2019; Barbosa, 2016).

É preciso um olhar para além do encantamento que a resiliência protagonizada por estes sertanejos proporciona com suas histórias de vida, e perceber aí a tragédia das políticas de educação, especialmente a cearense, à época com os piores indicadores de analfabetismo do país (Rodrigues, 2007). Os mesmos eram tão precários, que jovens viram melhor oportunidade em estudar em casa de farinha e embaixo de pés de árvores, do que dentro de uma escola. Na falta de professores deram aulas uns aos outros. E sem subsídios para sua escolarização, contaram com uma rede solidária e comunitária para suprir suas necessidades mais elementares (Rodrigues, 2007). Nas entrelinhas dessa surpreendente narrativa de superação há uma brutal marginalização dessa população em acessar a educação formal.

As condições que levaram à existência do Movimento Prece estão relacionadas a essa precária atuação do Estado, que ao priorizar o mercado, minimizando seu próprio papel, acarretou na fragilização das políticas públicas, como as de educação, atingindo especialmente os mais pobres. Nesse contexto de ausências estatais é comum o surgimento de iniciativas de ordem privada, algumas mais alinhadas ao mercado e outras conectadas a movimentos sociais (Dagnino, 2002).

Uma segunda compreensão é sobre a relevância dos conteúdos dos marcos legais e regulatórios na composição das políticas públicas. Como é possível perceber, ao seguir a cronologia do contexto de surgimento da EEEP Alan Pinho Tabosa, o avanço de legislações das políticas de educação viabilizaram melhorias na sua execução. Em 2007 o Estado do Ceará celebra convênio junto ao Fundo Nacional de Desenvolvimento da Educação (Lei n 11.494/2007) (Brasil, 2007a) e ao Brasil Profissionalizado (Decreto $n^{\circ}$ 6.302/2007c) o que viabilizou recursos para a construção e implantação das Escolas Estaduais de Educação Profissional (EEEP).

As EEEP foram criadas pela Lei estadual n 14.273/08 (Ceará, 2008) “[...] sendo-Ihes asseguradas as condições pedagógicas, administrativas e financeiras para a oferta de ensino médio técnico e outras modalidades de preparação para o trabalho". Atualmente já foram implantadas 122 escolas profissionais em todas as regiões do Estado do Ceará.

Já no ensino superior é interessante destacar o conjunto de medidas que possibilitaram o acesso e permanência de estudantes de origem popular na universidade, como o Reuni (Decreto $n^{\circ}$ 6.096/2007) (Brasil, 2007b); o PNAES (Decreto $n^{\circ}$ 7234/2010) (Brasil, 2010) e a Lei das Cotas (Lei n 12.711/2012) (Brasil, 2012). No Estado do Ceará isso possibilitou a expansão do Instituto Federal de Educação, Ciência e Tecnologia do Ceará (IFCE) em 35 campi distribuídos em cidades do interior do estado, a criação de duas universidades públicas: Universidade da Integração Internacional da Lusofonia Afro-Brasileira (Unilab) em 2010 e Universidade Federal do Cariri (UFCA) em 2013. Além da ampliação de vagas, cursos e campi da Universidade Federal do Ceará.

Nesse período de notórios avanços nas políticas de educação, o Movimento Prece também passou por transformações, organizou-se em associações estudantis, chamadas de EPCs - Escolas Populares Cooperativas, formando uma rede com centenas de estudantes, universitários e profissionais. Barbosa $(2016$, p. 9) afirma “O PRECE estimula que os jovens 
universitários contribuam com a aprendizagem dos estudantes de suas localidades, gerando uma rede de solidariedade e cooperação entre eles".

Com a expansão da UFC houve uma fusão dessas ações com programas universitários como o Conexões dos Saberes, o Programa de Aprendizagem Cooperativa em Células Estudantis (PACCE) e o Programa de Estímulo a Cooperação na Escola (PRECE), que levou a mesma sigla do Movimento (Andrade Neto et al., 2019; Ribeiro, 2018, Leão, 2019). À medida que esses universitários graduavam-se, passaram a atuar como profissionais na rede pública de educação. Assim, o surgimento da experiência da escola EEEP Alan Pinho Tabosa foi resultante da concomitância de papéis desses "precistas" que, simultaneamente, possuíam vinculações com UFC, SEDUC e Movimento Prece. Neste entrelaçamento forjaram uma atuação interinstitucional e constituíram dentro da escola uma metodologia ativa de aprendizagem centrada no protagonismo, cooperação e solidariedade entre os estudantes (Andrade Neto et al., 2019; Carvalho \& Andrade Neto, 2019).

A partir de 2011, foi realizado um conjunto de formações para estudantes, professores e gestores das escolas estaduais. A EEEP Alan Pinho Tabosa sistematizou suas concepções educativas na Aprendizagem Cooperativa e Solidária e tornou-se uma referência local², nacional ${ }^{3}$ e internacional ${ }^{4}$ de inovação pedagógica (Leão, 2019; Andrade Neto, 2018; Ribeiro, 2018; Matos, 2018; Bitu, 2014).

Uma terceira compreensão diz respeito às especificidades de cada política pelas peculiaridades de suas trajetórias regionais, locais e institucionais, de modo que os macro contextos assumem formatações únicas nos equipamentos. Um exemplo disso pode ser percebido ao analisar os efeitos da atual conjuntura política brasileira e como a mesma acarretou efeitos diretos sobre a EEEP Alan Pinho Tabosa devido a um fluxo de correlações políticas locais e institucionais dentro da universidade.

A última etapa de novas reconfigurações conjunturais na história contemporânea do Estado brasileiro inicia em 2016 com o impeachment de Dilma Rousseff, do PT, em um contexto de crise e estagnação econômica e fortalecimento de grupos políticos conservadores (Calixtre \& Fagnani, 2017). Analistas sociais como Carvalho et al. (2018, p. 27) têm compreendido que o impeachment foi “[...] um golpe de Estado jurídico-parlamentar-midiático, a desencadear a implementação intensiva de políticas neoliberais, com o desmonte de direitos e recuos das políticas sociais", sendo esta uma marca indelével das gestões sucessórias, Michel Temer (PMDB) e Jair Bolsonaro (sem partido).

Um ícone dessas proposições reformistas é a Proposta de Emenda à Constituição n ${ }^{\circ} 55$ de 2016 (PEC do teto dos gastos públicos), representando uma série de restrições às políticas públicas. Na Educação, seu impacto será melhor perceptível a médio e longo prazos, uma vez que está em vigência o decênio do Plano Nacional de Educação (Lei N 13.005/2014) (Brasil, 2014) até 2024. Contudo, algumas reformas já vêm acontecendo como a nova Base Nacional Comum Curricular, Novo Ensino Médio e Novo Fundeb. Todos aprovados após retificações conseguidas após intensas lutas por parte de educadores, pesquisadores e militantes da educação.

Esse contexto nacional de mudanças nas políticas de educação chega de forma diluída a nível estadual, uma vez que houve uma continuidade da gestão do Governo do Estado do Ceará. Por outro lado, na Universidade Federal do Ceará os primeiros reflexos começaram a chegar e um deles foi o processo de nomeação da atual reitoria, em 2019. Professores, técnicos e estudantes da UFC elegeram com cerca de $60 \%$ dos votos o professor Custódio Almeida para o cargo de reitor. Contudo, à revelia dessa indicação coletiva, foi nomeado pela presidência da república o atual reitor Cândido Albuquerque, gerando uma série de conflitos dentro da comunidade acadêmica (SINTUFCE, 2019).

\footnotetext{
2 Realização de Jornada Formativa com professores da rede pública cearense (UFC, 2018).

3 Série "Sementes da educação" (Videocamp, 2020).

${ }^{4}$ Rede internacional de Escolas Transformadoras (Brand, 2020).
} 
Após esse ocorrido, em audiência pública na Câmara Federal ${ }^{5}$ em homenagem aos 25 anos do Movimento Prece, o professor Manoel Andrade assumiu publicamente a parceria histórica do professor Custódio Almeida na implantação da Aprendizagem Cooperativa da UFC. Tomando isso em consideração, pede sua exoneração da Coordenadoria de Articulação da Universidade e educação básica, finalizando o programa Prece/UFC e a atuação em 60 escolas do Governo do Estado e Prefeitura de Fortaleza.

Com o recente fim dessa parceria com a UFC, a EEEP Alan Pinho Tabosa tem se reconfigurado, estabelecendo novos caminhos que serão objetos de investigação da última etapa dessa pesquisa que consiste adentrar o espectro temporal e territorial dos sujeitos. A próxima dimensão de análise consiste em compreender as percepções, crenças e sentimentos de estudantes egressos da escola.

\section{Considerações finais}

Muitos são os desafios atuais na realização de políticas públicas de educação voltadas às juventudes por isso a relevância de compreender experiências como da Escola Estadual de Educação Profissional Alan Pinho Tabosa constituída através da atuação de jovens, profissionais e estudantes, que em sua concomitância de vinculação constituíram uma parceria interinstitucional entre a Universidade Federal do Ceará, a Secretaria Estadual de Educação do Ceará e o Movimento Prece/Instituto Coração de Estudante para implementação dessa escola e sua diferenciada proposição educacional.

Tendo em consideração curiosa característica, percebeu-se como necessária a utilização de uma abordagem avaliativa cujo paradigma fosse multidimensional, histórico e participativo, elegendo-se na presente investigação os pressupostos da avaliação em profundidade. É necessário pontuar que nesse trabalho foram apresentadas etapas analíticas iniciais de visualização do contexto político, econômico e social de implementação da política, seus principais marcos regulatórios, formais e informais, bem como os reflexos desses fatores sobre a trajetória institucional, delineando suas especificidades locais. A próxima etapa implica adentrar os espectros temporais e territoriais dos sujeitos da política, valendo-se de entrevistas, questionários e grupos focais, para apreender as percepções dos estudantes egressos da EEEP Alan Pinho Tabosa, tendo os mesmos papéis ativos na elaboração de tais resultados.

Por fim, o que se almeja com o presente relato é fortalecer a importância da discussão e utilização de diferentes modelos avaliativos nas políticas públicas, sobretudo aqueles que tragam perspectivas que consigam acompanhar a complexidade necessária às políticas públicas com juventudes, em especial a escola contemporânea.

\section{Fonte de financiamento}

Bolsa de financiamento para mestrando da Coordenação de Aperfeiçoamento de Pessoal de Nível Superior (CAPES).

\section{Conflito de interesse}

Não há.

\section{Referências}

Andrade Neto, Manoel, Avendaño, Arneide Andrade, \& Queiroz, Talita Feitosa Moisés. (2019). Guia Prático para Elaboração de Planos de Aula em Aprendizagem Cooperativa e Solidária - Técnica de Transição Metodológica - ETMFA. Fortaleza: Instituto Coração de Estudante.

Andrade Neto, Manoel. (2018). Pelos que ficaram pra trás e para os que estiveram comigo: Narrativa autobiográfica do Professor Manoel Andrade Neto, um matuto sonhador. Memorial para obtenção do título

\footnotetext{
${ }^{5}$ Audiência Pública na Câmara dos Deputados em Brasília no dia 27 de agosto de 2019 (YouTube, 2019).
} 
de Professor Titular do Departamento de Química Orgânica e Inorgânica da Universidade Federal do Ceará, Fortaleza. (texto não publicado).

Andrade, Ana Maria Teixeira. (2019). Narrativas de vida e formação de estudantes e lideranças do Programa de Educação em Células Cooperativas (Tese de doutorado). Recuperado em 28 fevereiro de 2020, de http://www.repositorio.ufc.br/handle/riufc/49549

Barbosa, Marília Studart. (2016). Relações entre os valores do Programa de Educação em Células Cooperativas (PRECE) e os valores pessoais de seus participantes (Dissertação de mestrado). Recuperado em 28 de fevereiro de 2020, de http://www.repositorio.ufc.br/handle/riufc/21860.

Bitu, Corina Bastos. (2014). Aprendizagem Cooperativa: Uma Análise da Escola Estadual de Educação Profissional Alan Pinho Tabosa (Dissertação de mestrado). Recuperado em 28 de fevereiro de 2020, de http://www.mestrado.caedufjf.net/wp-content/uploads/2014/12/CORINA-BASTOS-BITU.pdf.

Bourdieu, Pierre. (1989). Introdução a uma sociologia reflexiva. In Pierre Bourdieu. O poder simbólico. Lisboa: DIFEL.

Brand (2020). Transformadoras.com.br. Recuperado em 4 março de 2020, de transformadoras.com.br

Brasil. (2007a). Dispõe sobre o Fundo de Manutenção e Desenvolvimento da Educação Básica e de Valorização dos Profissionais da Educação - FUNDEB (Lei n 11.494, de 20 de junho de 2007). Diário Oficial [da] República Federativa do Brasil, Brasília. Recuperado em 28 de fevereiro de 2020, de http://www. planalto.gov.br/ccivil_03/_ato2007-2010/2007/lei//11494.htm

Brasil. (2007b). Institui o Programa de Apoio a Planos de Reestruturação e Expansão das Universidades Federais - REUNI (Decreto ${ }^{\circ}$ 6.096, de 24 de abril de 2007). Diário Oficial [da] República Federativa do Brasil, Brasília. Recuperado em 22 julho de 2021, de http://www.planalto.gov.br/ccivil_03/_ato2007-2010/2007/ decreto/d6096.htm

Brasil. (2007c). Dispões sobre Brasil Profissionalizado (Decreto $n^{\circ}$ 6.302, de 12 de dezembro de 2007). Diário Oficial [da] República Federativa do Brasil, Brasília. Recuperado em 28 fevereiro de 2020, de http:// www.planalto.gov.br/ccivil_03/_Ato2007-2010/2007/Decreto/D6302.htm

Brasil. (2010, julho 20). Dispõe sobre o Programa Nacional de Assistência Estudantil - PNAES (Decreto ${ }^{\circ}$ 7.234, de 19 de julho de 2010). Diário Oficial [da] República Federativa do Brasil, Brasília. Recuperado em 20 de fevereiro 2020, de http://www.planalto.gov.br/ccivil_03/_ato2007-2010/2010/decreto/d7234.htm

Brasil. (2012). Dispõe sobre o ingresso nas universidades federais e nas instituições federais de ensino técnico de nível médio e dá outras providências (Lei n 12.711/2012, de 29 de agosto de 2012). Diário Oficial [da] República Federativa do Brasil, Brasília. Recuperado em 26 de agosto de 2020, de http://portal.

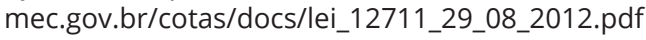

Brasil. (2014). Aprova o Plano Nacional de Educação - PNE e dá outras providências (Lei n 13.005/2014). Diário Oficial [da] República Federativa do Brasil, Brasília. Recuperado em 22 julho de 2020, de http://pne. mec.gov.br/18-planos-subnacionais-de-educacao/543-plano-nacional-de-educacao-lei-n-13-005-2014.

Calixtre, André, \& Fagnani, Eduardo. (2017, Maio). A política social e os limites do experimento desenvolvimentista (2003-2014) (No. 295, Texto para Discussão). Campinas: Instituto de Economia da UNICAMP. Recuperado em 17 de fevereiro de 2021, de https://www.ncst.org.br/images_news/files/ conteudo-anexado.pdf

Carvalho, Alba Maria Pinho de, Milanez, Bruno, \& Guerra, Eliana Costa. (2018). Rentismo-neoextrativismo: a inserção dependente do Brasil nos percursos do capitalismo mundializado (1990-2017). In: Raquel Maria Rigotto, Ada Cristina Pontes Aguiar, \& Lívia Alves Dias Ribeiro (Orgs.), Tramas para a justiça ambiental: Diálogo de saberes e práxis emancipatória. Fortaleza: Edições UFC.

Carvalho, Alba Maria Pinho, \& Gussi, Alcides Fernando. (2011, março). Perspectivas contemporâneas em avaliação de políticas públicas (Mesa redonda). In Seminário MAPP. Fortaleza: Universidade Federal do Ceará. Auditório José Albano.

Carvalho, Frank Viana, \& Andrade Neto, Manoel. (2019). Metodologias Ativas: Aprendizagem cooperativa, $P B L$ e pedagogia de Projetos. São Paulo: República do Livro.

Castro, Lúcia Rabelo. (2006). Admirável Mundo Novo: a cadeia das gerações e as transformações do contemporâneo. In: Dominique Colinvaux, Luci Banks Leite \& Débora Dalbosco Dell'Aglio (Orgs.), Psicologia do desenvolvimento: Reflexos e práticas atuais. São Paulo: Casa do Psicólogo.

Ceará. Governo do Estado. (2008, dezembro 23). Dispõe sobre a criação das Escolas Estaduais de educação profissional - EEEP, no âmbito da Secretaria de Educação, e dá outras providências (Lei nº 14.273, de 19 de dezembro de 2008). Diário Oficial do Estado, Fortaleza.

Cruz, Danielle Maia. (2019). Enfoques contra-hegemônicos e pesquisa qualitativa: desafios da avaliação em profundidade em políticas públicas. AVAL Revista Avaliação de Políticas Públicas, 1(15), 161-173.

Dagnino, Evelina. (2002). Sociedade Civil, Espaços Públicos e a Consolidação Democrática no Brasil: limites e possibilidades. In Evelina Dagnino. Sociedade Civil e Espaços Públicos no Brasil. São Paulo: Paz e Terra.

Denzin, Norman Kent; Lincoln, Yvonna Senssions. (2012). Controversias paradigmáticas, contradicciones y confluências emergentes. In: Denzin, Norman Kent \& Lincoln, Yvonna Senssions. Paradigmas y perspectivas en disputa: Manual de investigación cualitativa (Vol. 2). Buenos Aires: GEDISA editorial.

Gonçalves, Alícia Ferreira. (2008). Políticas públicas, etnografia e a construção dos Indicadores socioculturais. AVAL Revista Avaliação de Políticas Públicas, 1(1), 17-27. 
Gussi, Alcides Fernando (2014). Avaliação de políticas públicas sob uma perspectiva antropológica. In: Valente, Heloísa de Araújo; Prados, Rosália Maria Netto. Schimidit, Cristina. (Org.). A música como negócio. São Paulo: Letra e Voz.

Gussi, Alcides Fernando, \& Oliveira, Breynner Ricardo de. (2015) Discutindo paradigmas contrahegemônicos de avaliação de políticas públicas. In: Anais do $1^{\circ}$ Encontro Nacional de Ensino e Pesquisa do Campo de Públicas. Brasília: Associação Nacional de Ensino e Pesquisa do Campo de Públicas.

Jannuzzi, Paulo de Martino. (2016). Monitoramento e Avaliação de Programas Sociais: Uma introdução aos conceitos e técnicas. Campinas: Alínea.

Kuhn, Thomas Samuel. (2013). A prioridade dos paradigmas. A estrutura das revoluções científicas. São Paulo: Perspectiva.

Leão, Dóris Sandra Silva. (2019). Avaliação da proposta da aprendizagem cooperativa como estratégia teórico-metodológica para melhorar o ensino-aprendizagem: Estudo de caso em uma escola estadual de educação profissional do Ceará (Tese de doutorado). Recuperado em 28 fevereiro de 2020, de http://www. repositorio.ufc.br/handle/riufc/46018.

Lejano, Raul Perez. (2011). Parâmetros para análise de políticas públicas: A fusão de texto e contexto. Campinas: Editora Arte Escrita.

Matos, Catarina da Graça Almeida. (2018) Aprendizagem cooperativa em sala de aula na EEEP Alan Pinho Tabosa-CE e sua relação com uma cultura de paz, sob a ótica das juventudes. 2018 (Dissertação de mestrado). Recuperado em 27 de julho de 2021, de http://www.repositorio.ufc.br/handle/riufc/39000.

Mészáros, István. (2011). Para além do capital: Rumo a uma teoria da transição. São Paulo: Boitempo.

Morin, Edgar. (2003). Educar na era planetária: O pensamento complexo como método de aprendizagem no erro e na incerteza. São Paulo: Cortez.

Paulani, Leda Maria. (2012) A inserção da economia brasileira no cenário mundial: uma reflexão sobre a situação atual à luz da história. In: Boletim de economia e política internacional/Instituto de Pesquisa Econômica Aplicada. Diretoria de Estudos e Relações Econômicas e Políticas Internacionais. n.10, Abr.|Jun. 2012.

Ribeiro, Tony Wérison de Sousa Ramos. (2018). Capital social e participação política: A experiência de empoderamento cidadão de egressos da rede de associações do PRECE/CE (Dissertações de mestrado). Recuperado em 28 fevereiro de 2020, de http://www.repositorio.ufc.br/handle/riufc/43212

Rodrigues, Francisco Antônio Alves. (2007). Instituto Coração de Estudante: Educação e mudanças sociais, políticas e culturais em comunidades rurais em Pentecoste-CE (Dissertação de mestrado). Recuperado em 26 julho de 2021, de http://www.repositorio.ufc.br/handle/riufc/3140

Rodrigues, Lea Carvalho (2014). Por uma Avaliação em Profundidade de Políticas e Programas Sociais: Diálogos com Experiências de Pesquisa. In: Arcoverde, Ana Cristina Brito (Org.). Dimensões, Interfaces e Práticas de Avaliação de Políticas Públicas. 1 ed. Recife: Editora Universitária da UFPE.

Rodrigues, Lea Carvalho. (2016). Método experiencial e avaliação em profundidade: Novas perspectivas em políticas públicas. Revista Desenvolvimento em Debate, 4(1), 103-155.

Silva, Maria Ozanira da Silva e. (2012) Construindo uma proposta metodológica participativa para desenvolvimento da pesquisa avaliativa: uma contribuição da teoria crítica para a prática do Serviço Social. Textos \& Contextos. v. 11, n. 2, p. 222 - 233, ago./dez.

Sindicato dos Trabalhadores das Universidades Federais no Estado do Ceará - SINTUFCE. (2019). Professor Custódio Almeida obtém maioria dos votos em consulta à comunidade universitária para escolha de reitor da UFC. Recuperado em 9 de maio de 2021, de https://www.sintufce.org.br/noticias/909-professor-custodioalmeida-obtem-maioria-dos-votos-em-consulta-a-comunidade-universitaria-para-escolha-de-reitor-da-ufc

Universidade Federal do Ceará - UFC. EIDEIA - Escola Integrada de Desenvolvimento e Inovação Acadêmica. (2018). Prece divulga resultado final da seleção para a Jornada Formativa 2018. Recuperado em 25 de agosto de 2020, de https://eideia.ufc.br/pt/prece-divulga-resultado-final-da-selecao-para-ajornada-formativa-2018/

Videocamp. (2020). Sementes da educação (Série documental). Recuperado em 25 de agosto de 2020, de https://www.videocamp.com/pt/movies/ep-9-sementes-da-educacao-eeep-alan-pinho-tabosa

YouTube. (2019). Educação - Programa de Estímulo e Cooperação na Escola [Vídeo]. Recuperado em 28 de fevereiro de 2019, de https://www.youtube.com/watch?v=52NhjjAVY2U 